Heijmans, M., Waverijn, G., Rademakers, J., Vaart, R. van der, Rijken, M. Functional, communicative and critical health literacy of chronic disease patients and their importance for

\begin{tabular}{|l|l|}
$\begin{array}{l}\text { Postprint } \\
\text { Version }\end{array}$ & 1.0 \\
\hline Journal website & http://linkinghub.elsevier.com/retrieve/pii/S0738-3991(14)00413-3 \\
\hline Pubmed link & http://www.ncbi.nlm.nih.gov/pubmed/25455794 \\
\hline DOI & 10.1016/j.pec.2014.10.006 \\
\hline
\end{tabular}

This is a NIVEL certified Post Print, more info at http://www.nivel.eu

\title{
Functional, communicative and critical health literacy of chronic disease patients and their importance for self-management
}

\author{
MONIQUE HEIJMANS ${ }^{A,}$, GEEKE WAVERIJN ${ }^{A}$, JANY RADEMAKERS ${ }^{A}$, ROSALIE VAN DER \\ VAART $^{\mathrm{B}}$, MIEKE RIJKEN ${ }^{\mathrm{A}}$
}

\begin{abstract}
Objective: To provide insight into the level of health literacy among chronic disease patients in the Netherlands, to identify subgroups with low literacy and to examine the associations between health literacy and self-management.

Methods: Self-report questionnaires were sent to a nationwide sample of 1.341 chronic disease patients. The Dutch Functional Communicative and Critical Health Literacy scale (FCCHL), the Partners in Health scale (PIH) and Perceived Efficacy in Patient-Doctor Interactions (PEPPI-5) were used to assess health literacy and aspects of self-management.

Results: In general, health literacy skills were good. A higher age, lower education, lower income, multi-morbidity and/or functional limitations were associated with lower levels of health literacy. Communicative and critical health literacy were related to some aspects of self-management but not to all. Functional health literacy was less important.

Conclusion: Communicative and critical health literacy play a role in successful self-management of chronic disease but the impact differs by context. Health literacy levels vary according to socio-demographic and disease characteristics of patients.

Practice implications: Health care professionals should tailor their information and support to the health literacy skills and personal context of their patients.
\end{abstract}

\section{INTRODUCTION}

During the last decades there has been a growing interest in the concept of health literacy, together with an increased emphasis on individual responsibility for health and self-management of chronic illness [1] and [2]. A number of reviews have pointed to the importance of health literacy as a factor to maintain or improve health [3] and [4]. The specific relationship between health literacy and self-management of chronic illness has been studied less often. The aim of the present study is to contribute to the knowledge on health literacy and self-management by providing 
Heijmans, M., Waverijn, G., Rademakers, J., Vaart, R. van der, Rijken, M. Functional, communicative and critical health literacy of chronic disease patients and their importance for self-management. Patient Education and Counseling: 2015, 98(1), 41-48

insight into the level of health literacy among chronic disease patients in the Netherlands, to identify subgroups that are less literate and by examining the association between health literacy and aspects of self-management.

Health literacy has been defined and conceptualized in many different ways [5] and [6], and its nature and scope have been changed and widened during the last decade [7]. Early definitions focused on the ability to apply reading, writing and numeracy skills to health related materials such as prescriptions, appointment cards and medicine labels [7], [8] and [9], while later conceptualizations encompassed a range of skills, including social and communication skills that enable people to obtain, understand and use health information in ways that enhance health, wellbeing and engagement in medical decision making [10], [11] and [12]. More recent definitions also include the ability to apply these skills in various settings and across the life span [13].

Although definition and operationalization of health literacy vary, reviews have shown that lower levels of health literacy are consistently associated with a wide range of health related outcomes, including higher mortality, worse general health, poor healthcare access, more hospitalizations and greater use of emergency care, higher health care costs [14], greater difficulty participating in shared decision/making, and a worse medication adherence and self-management in general [3], [4] and [15]. Moreover, low health literacy has been found to be especially prevalent in the elderly, those with low socio-economic status and minority groups [4] and [16] and is recognized as a strong contributor to health inequalities [17].

A model of health literacy that is of specific interest in the context of selfmanagement of chronic illness is the model proposed by Nutbeam [12]. This model distinguishes between three different types of health literacy: functional, communicative and critical health literacy. These types of health literacy each require different skills to obtain, understand and use information. The skills have an ascending order of difficulty that are supposed to progressively lead to greater autonomy and empowerment of patients and to a greater role in medical decisionmaking [18]. Functional literacy refers to the basic level of reading and writing skills to obtain, understand and use factual information on for example health risks, medication prescriptions or how to use the health care system. Communicative or interactive literacy refers to advanced skills that allow a person to extract information, derive meaning from different sources of communication, and apply new information to changing circumstances. Critical health literacy refers to more advanced skills for critically analyzing and reflecting on information or advice received and using information to exert greater control over life events and situations [12].

Studies exploring the specific relationships between functional, communicative and critical health and self-management are scarce. Most studies on health literacy and self-management focus on functional health literacy [3], [5], [19] and [20]. Findings from these studies are inconsistent [21] and it is suggested that optimal selfmanagement may not depend solely on a patient's ability to read health information [15], [21] and [22]. Functional health literacy is important but greater value may be 
Heijmans, M., Waverijn, G., Rademakers, J., Vaart, R. van der, Rijken, M. Functional, communicative and critical health literacy of chronic disease patients and their importance for self-management. Patient Education and Counseling: 2015, 98(1), 41-48

found in assessing health literacy beyond the functional level to explore barriers in self-management for chronic patients, including the ability to extract, compare, communicate and critically analyze information. There have been a few, small studies among diabetes patients [22], [23] and [24] conducted in Japan, assessing all three types of health literacy, which all found that functional health literacy is less important than communicative and critical health literacy for diabetes selfmanagement.

Most research on health literacy has been conducted in the United States and Japan. As a consequence, relatively little is known about the level of health literacy and its effects on outcome measures in European countries and more specifically, the Netherlands [20] and [25]. Recent results from the European Health Literacy Survey showed that the percentage of the general Dutch population with limited health literacy skills is about 29\% [26]. More specific insight into these skills is important however, as low health literacy may cause a gap between what is expected of chronic patients with respect to self-management and their actual skills. By identifying vulnerable groups with respect to health literacy, professionals can tailor their information and support to the health literacy skills of their patients.

The aims of the present study were threefold: (1) to provide insight into the functional, communicative and critical health literacy skills of chronic somatic disease patients in the Netherlands, (2) to identify groups that are less literate and (3) to examine the relationship between health literacy and aspects of self-management. Based on earlier findings [22], [23] and [24], we hypothesize that communicative and critical health literacy contribute more to better self-management than functional health literacy of chronic patients.

\section{METHODS}

\subsection{Sample}

We analyzed data from the 'National Panel of people with Chronic illness or Disability' (NPCD), a nationwide prospective panel-study on the consequences of chronic illness in the Netherlands [27]. Panel members were recruited from the patient files of general practices (national random samples of general practices, drawn from the Netherlands registration of General Practice [28]). Selection criteria for patients were: diagnosis of a somatic chronic disease by a certified medical practitioner, aged $\geq 15$ years, being non institutionalized, being aware of the diagnosis, not being terminally ill (life expectancy $>6$ months according to the GP), being mentally able to participate, and having sufficient mastery of the Dutch language. Patients who met the selection criteria were invited by their general practitioner to participate in the panel-study (for a maximum of 4 years). Patients who agreed to participate filled in self-report questionnaires twice a year. In addition, their general practitioner provided medical data at inclusion. The panel can be considered a representative sample of the Dutch non-institutionalized chronically ill population of 15 years and older. NPCD is registered with the Dutch Data Protection Authority; all data were collected and handled in accordance with the privacy protection guidelines of the authority. 
Heijmans, M., Waverijn, G., Rademakers, J., Vaart, R. van der, Rijken, M. Functional, communicative and critical health literacy of chronic disease patients and their importance for self-management. Patient Education and Counseling: 2015, 98(1), 41-48

Data for this study were derived from a questionnaire sent in April 2013 to a sample of 1.681 chronically ill panel members, of which $1.341(80 \%)$ returned the questionnaire. Non-response analysis revealed no differences between responders and non-responders in relevant background characteristics (sex, educational level, living situation, health status, number and type of chronic conditions, illness duration) except for age: responders were somewhat older than non-responders.

\subsection{Measures}

\subsubsection{Health literacy}

A Dutch translation of the Functional Communicative and Critical Health Literacy scale (FCCHL) by Ishikawa [22] and [29] was used to assess health literacy skills. We used an adapted version by van der Vaart (unpublished) in which a few changes were made compared to the original Japanese scale based on the results of two validation studies in the Netherlands [25] and [29]. Changes concerned the clarity of the statements and the response options. The response options of the items for communicative and critical health in the adapted version are no longer based on the occurrence of behavior ("never" to "often") but on experienced difficulty in performing health literacy behavior ("easy” to "rather difficult”).

The FCCHL-Dutch consists of 14 statements with 4 points Likert scales (1-4). The statements ask how often (never to often) patients have trouble with reading or understanding leaflets from healthcare providers/hospital or pharmacy (functional health literacy; 5 items), have difficulty (easy to rather difficult) performing certain actions in relation to health information (communicative (5 items) and critical (4 items) health literacy). Mean scale scores were obtained by summing (reversed) item scores and dividing them by the total number of items, resulting in a score ranging from 1 (low health literacy) to 4 (high health literacy). Patients had to fill in at least 4 items of the functional and communicative health literacy scales and 3 items of the critical health literacy scale to get a scale score.

\subsubsection{Self-management}

A Dutch version of the 12 item self-rated Partners in Health scale (PIH-Dutch) was used to assess patients' self-management knowledge and behaviors. The 'Partners in Health Scale' has been developed within the Australian 'Flinders Program of Chronic Care Self Management' (CCSM). The items assess for example to what extent patients have knowledge of their condition, actively participate in decisionmaking, feel able to monitor and manage symptoms, manage the physical, emotional and social consequences, and adopt lifestyles that promote health. Scores range from zero to eight with higher scores pointing to better self-management. As the content of the items of the Dutch version is slightly different from the original version we conducted an exploratory factor analysis to identify underlying constructs. Using varimax rotation, a four factor solution explaining $66 \%$ of the variance was identified. These factors were coping with consequences ( 4 items, $\alpha=.85$ ), active role in treatment ( 4 items, $\alpha=.69$ ), knowledge ( 2 items, $\alpha=.89$ ) and recognition and management of symptoms ( 2 items, $\alpha=.66$ ). This factor structure very much 
Heijmans, M., Waverijn, G., Rademakers, J., Vaart, R. van der, Rijken, M. Functional, communicative and critical health literacy of chronic disease patients and their importance for self-management. Patient Education and Counseling: 2015, 98(1), 41-48

resembles the factor structure found in the original Australian version [30]. niver Correlations between scales ranged from .22 to .34. Scores for each scale and a total score were used for this study.

\subsubsection{Confidence in acting in medical consultations}

Patients' confidence in interacting with their main care provider was assessed using the short 5-item version of the Perceived Efficacy in Patient-Doctor Interactions (PEPPI-5) scale [31] and [32]. Patients indicated on a 5-point Likert scale (1 = not at all confident, to $5=$ completely confident) how confident they were that they e.g. knew which questions to ask or were able to make the most out of the visit ( $\alpha=.95$ ). A total score ranging from 1 to 5 was used in this study, with higher scores being indicative of more confidence in consultations. The PEPPI correlated .46 with the PIH-total score.

\subsubsection{Socio-demographic and disease characteristics}

Socio-demographic information of the patients included sex, age, education level, household type and income. Education level was based on the highest level of education accomplished, and categorized in three categories: low (primary school or preparatory vocational training), intermediate (intermediate or advanced general education or intermediate vocational training) and high (high vocational education or university).

Disease characteristics included type and number of chronic diseases, illness duration and the presence of physical disabilities. Type of disease was derived from patients' GP records and registered as ICPC codes [33]. We distinguished eight categories: cardiovascular diseases, lung diseases, diabetes, cancer, musculoskeletal diseases, digestive diseases, neurological diseases and other diseases. In case of patients having more than one chronic disease, we used the first diagnosed disease to classify the participants according to disease type. The number of chronic diseases registered by the GP was categorized as one, two, and three or more chronic diseases. Illness duration was derived from the medical data provided by the general practitioners of the participants in the panel-study (with their permission). A variable was constructed by subtracting the year in which the (first) chronic disease had been diagnosed from the year of measurement. At inclusion, patients filled in a screener for the presence and severity of long-term physical disabilities [34]. Patients were divided into two groups: those without disabilities or with mild disabilities only and those with moderate or severe disabilities. Patients with moderate disabilities have difficulty with several activities, for example walking or dressing, but still can carry out these activities independently. A person with severe disabilities is unable to perform one or more activities independently.

\subsection{Statistical analysis}

The internal consistency of the three scales and the distributional properties of the FCCHL were assessed, using Cronbach's alpha as a measure of internal consistency. Floor or ceiling effects were considered to be present if $>15 \%$ of the patients scored 
Heijmans, M., Waverijn, G., Rademakers, J., Vaart, R. van der, Rijken, M. Functional, communicative and critical health literacy of chronic disease patients and their importance for self-management. Patient Education and Counseling: 2015, 98(1), 41-48

the best or worse possible score [35]. In addition, we conducted a confirmatory factor analysis to test whether the health literacy scales assess the theoretically distinguished three health literacy dimensions. To examine the model fit the comparative fit index (CFI), the standardize root mean square residual (SRMR), and the root mean square measure of approximation (RMSEA) were used. NNFI and CFI values $\geq 0.95$, SRMR $\leq 0.08$ and RMSEA values $\leq 0.06$ were considered indicative of good model fit [36].

Descriptives were used to describe our study sample and their scores on the FCCHL, $\mathrm{PIH}$ and PEPPI. Bivariate associations between the FCCHL and socio-demographic characteristics and disease characteristics were examined using independent sample $T$-tests and one-way ANOVA. Stepwise multiple regression analysis was performed to analyze the independent effect of levels of health literacy on aspects of selfmanagement (Step 2) (PIH-scale scores, PIH total score and PEPPI total score) after adjusting for demographic and disease characteristics (Step1). All analyses were performed using the Statistical Package for the Social Sciences, Version 18. For the confirmatory factor analysis LISREL 8.70 (Scientific Software International, Lincolnwood, IL) was used.

\section{RESULTS}

\subsection{Sample characteristics}

In Table 1, sample characteristics are shown. Mean age was 62 years with $55 \%$ of the sample being female. Most patients had been diagnosed for quite a long time ( $M=12$ years) but with a large variation in illness duration (range 0-67 years). Half of the patients suffered from multi-morbidity, one-third experienced moderate to severe functional limitations. Mean scores on the PIH subscales and total scales and on the PEPPI were high indicating that patients perceived their abilities for selfmanagement and their confidence in medical consultations as quite high.

\section{[TABLE 1]}

\subsection{Reliability, distributional properties and structural validity of the FCCHL}

Confirmatory factor analysis showed good fit indices for the 3-factor model in our sample with NNFI $=.99$, CFI $=.99$, SMSR $=.002$ and RMSEA of 0.05 .

Standardized factor loadings ranged between .70 and .99 (Fig. 1). Internal consistency of the three health literacy scales were good with $\alpha=.90$ for functional health literacy, $\alpha=.88$ for communicative health literacy and $\alpha=.93$ for critical health literacy. Ceiling effects were found for functional and communicative health literacy: respectively $17 \%$ and $19 \%$ had a mean scale-score of 4 .

\section{[FIGURE 1]}

\subsection{Health literacy scores}

Patients' health literacy scores were generally high (Table 2). Patients scored best on functional health literacy, followed by communicative and critical health literacy. 
Heijmans, M., Waverijn, G., Rademakers, J., Vaart, R. van der, Rijken, M. Functional, communicative and critical health literacy of chronic disease patients and their importance for self-management. Patient Education and Counseling: 2015, 98(1), 41-48

Over $80 \%$ of the respondents indicated that they never or only sometimes have nivel trouble with reading or understanding leaflets from healthcare providers/hospital or pharmacy (functional health literacy). An equal percentage finds it easy or rather easy to collect and extract information from different sources, to communicate their thoughts about it with others and to apply the information in daily life (communicative health literacy). Critical health literacy skills are (rather) difficult for almost half of the respondents however: they have difficulty considering the applicability, validity and reliability of the information and to collect information to make health decisions.

\section{[TABLE 2]}

\subsection{Differences in health literacy scores by demographic- and disease characteristics}

There were significant differences in all three health literacy levels between subgroups of patients differing in age, education level, income, number of chronic diseases and severity of functional disabilities (Table 3). In general, lower levels of functional, communicative and critical health literacy were found for patients who were older, had a low education, a lower income, suffered from multimorbidity or experienced moderate to severe functional limitations. In addition, a weak negative relationship was found between illness duration and literacy skills. Type of illness was not related to health literacy. Patients living alone scored lower on the communicative health literacy scale than patients living together with a partner and/or children.

\section{[TABLE 3]}

\subsection{Health literacy and self-management}

Bivariate correlations between functional, communicative and critical health literacy and aspects of self-management were all significant ranging from .07 to .35. In general, correlations were stronger for communicative and critical health literacy than for functional health literacy (not in table). Table 4 shows the results of the regression analyses to predict aspects of self-management and perceived confidence in medical consultations. Health literacy made small to moderate contributions (4$15 \%$ ) to the variance in outcome measures when demographic and disease characteristics were taken into account. In general, patients with better health literacy skills are thus more likely to exhibit better self-management and experience more confidence in medical consultations. Communicative health literacy showed the strongest correlations with all outcome measures, followed by critical health literacy. Functional health literacy contributed to a better way to cope with the consequences of a chronic illness, to more knowledge and to more confidence during consultations with professionals, but not to more active involvement in treatment or a better recognition and management of symptoms. Critical health literacy made a significant contribution to perceived knowledge, an active role in treatment, general selfmanagement and confidence in medical consultations. Considering the contribution of socio-demographic and disease related variables to self-management, the presence of moderate to severe physical disabilities hinders coping with the consequences of a 
Heijmans, M., Waverijn, G., Rademakers, J., Vaart, R. van der, Rijken, M. Functional, communicative and critical health literacy of chronic disease patients and their importance for self-management. Patient Education and Counseling: 2015, 98(1), $41-48$

chronic disease and self-management in general, whereas for older people this seems more easy.

\section{[TABLE 4]}

\section{DISCUSSION AND CONCLUSION}

In this cross-sectional study among a large Dutch sample of chronic disease patients we investigated the level of functional, communicative and critical health literacy and their associations with chronic disease self-management. Results showed that patients in the Netherlands experience their health literacy as quite good, with patients scoring best on functional health literacy, followed by communicative and critical health literacy, providing support for Nutbeam's model that the three types of health literacy have an ascending level of difficulty and complexity [11]. Our findings are also consistent with findings from the European Health Literacy Survey [27] in which people experienced items reflecting critical health literacy (e.g. judging the credibility of health information) as most difficult.

Like in other studies [4], [16] and [18], we found lower levels of health literacy among certain subgroups of chronic patients: elderly patients, patients with less education, lower incomes, multimorbidity and/or functional limitations reported lower levels of functional, communicative and critical health literacy. Because these people have less capacities to make sound decisions in the context of their everyday life, their ability to protect, maintain and increase control over their illness and health is diminished. Poor health, and worse health outcomes are consistently found among patients with more complex care needs and with a lower socioeconomic status. Our findings highlight the potential role of health literacy in this relationship.

Consistent with small studies among diabetes patients [22], [23] and [24], we found stronger relationships between communicative and critical health literacy and aspects of self-management than between functional health literacy and outcome measures, suggesting that higher order skills are more important for self-management than functional skills.

Communicative health literacy consists of higher-level communicative and social skills required to extract and discuss information with others. Patients with high skills are characterized by the self-confidence to act independently on advice, and to interact successfully with the health care system and providers [11]. Given this definition it is not surprising that we found the strongest relationships between communicative health and self-management. The Partners in Health scale, used in this study as a measure for self-management, includes many items about doing things (e.g. taking medicines, taking decisions about treatment, plan follow-up consults) in conjunction with the health care professional. Also confidence to act in medical consultations is likely to benefit most from communicative health literacy skills.

We did find some relationships between critical health literacy and self-management but they were less strong than for communicative health literacy. This is in contrast with Inoue et al. [23]) who found a strong relationship between critical health 
Heijmans, M., Waverijn, G., Rademakers, J., Vaart, R. van der, Rijken, M. Functional, communicative and critical health literacy of chronic disease patients and their importance for self-management. Patient Education and Counseling: 2015, 98(1), 41-48

literacy and self-efficacy among diabetics. Inouye focused on self-management activities outside the consultation room. It might be that critical health literacy is stronger related to activities that are dependent of individual capacities than to activities that are a shared responsibility of patient and professional. The FCCHL used in this study operationalizes critical health literacy as higher order cognitive skills in a medical context. In a recent paper, Sykes et al. [37] pointed to critical health literacy as a broader concept than just higher order cognitive skills in the context of acquiring and using health information. According to Sykes critical health literacy includes advanced personal and social skills, (health) knowledge, information skills, effective interaction between service providers and users, informed decision making and empowerment including political actions. In that way the broad definition of Sykes may better fit the reality of daily living with a chronic disease. Recently, a new instrument to measure health literacy has been developed that covers this broad definition: the Health Literacy Questionnaire, developed by Osborne et al. [38]. At the moment, we are translating this in Dutch and we will used this HLQ in future research to understand differences in self-management behavior.

As a whole, health literacy skills predicted more of the variance in all aspects of selfmanagement than did the demographic- and disease characteristics of patients, an exception being coping with daily physical, social and emotional consequences of a chronic illness which above all was determined by the functional limitations and the age of the patient. Nutbeam [11] already wrote that the extent to which health literacy is beneficial, is both context- and content-specific; different (health care) contexts require specific content knowledge and skills. This means that even those with high literacy skills may have difficulties in novel environments [39]. Or the other way around, as health literacy requirements vary according to the context and setting, the context is decisive for whether a person's health literacy skills contribute to their health or not. It is important to take both, the social environment of the patient as well as the setting into account when studying the effects of health literacy.

Some critical notes should be made about this study. Due to the cross-sectional design, conclusions about causality cannot be drawn. A written questionnaire was used, filled in at home. It is possible that some patients received some assistance completing the questionnaire or that we missed the people with very low literacy skills. On the other hand, our sample contained a relatively high percentage of people with low education: $32 \%$ as compared to $22 \%$ in the general population. Moreover, there was no systematic non-response except for age: non-responders were somewhat younger but this is more likely to decrease than increase the levels of health literacy. Another factor that might have influenced the levels of health literacy found, is illness duration. The majority of patients were ill for quite a long time and this may be the reason for the high levels of health literacy found as it has been suggested that patients become more experienced in understanding and communicating about health and health information, the longer they are ill [11]. We do believe however that the long illness duration is a correct reflection of the general illness duration of the chronically ill population in the Netherlands as patients were randomly selected, just on the basis of a medical diagnosis of a chronic disease and not on other criteria that might have influenced illness duration. 
Heijmans, M., Waverijn, G., Rademakers, J., Vaart, R. van der, Rijken, M. Functional, communicative and critical health literacy of chronic disease patients and their importance for self-management. Patient Education and Counseling: 2015, 98(1), $41-48$

\subsection{Conclusion}

This study among a large representative sample of chronic disease patients confirms the findings from the few small studies in diabetes patients: basic reading and writing skills are less important for successful self-management than more complex communicative and critical skills. We also found evidence that patients differ in their level of health literacy and identified a number of vulnerable groups. Health literacy skills are important for some aspects of self-management but not for others, highlighting the importance of context.

\subsection{Practical implications}

It is important that health care professionals tailor their information and support to the health literacy skills and specific context of their patients. How to measure health literacy in the context of chronic disease self-management needs further consideration given recent developments in definitions and theory. A focus on the medical context alone does not fit the broad area in which the daily management of a chronic illness takes place.

\section{ACKNOWLEDGEMENTS}

This study was based on data from the research program 'National Panel of people with Chronic illness or Disability’, which is financed by the Netherlands Ministry of Public Health, Welfare and Sports and the Netherlands Ministry of Social Affairs and Employment. These ministries had no role in the design and execution of the study. The authors declare that they have no competing interests.

\section{REFERENCES}

[1] P. Salmon, G.M. Hall Patient empowerment or the emperor's new clothes J R Soc Med, 97 (2004), pp. 53-56

[2] D. Nutbeam, I. Kickbusch Advancing health literacy: a global challenge for the 21st century Health Promot Int, 15 (2000), pp. 183-184

[3] D.A. DeWalt, N.D. Berkman, S. Sheridan, K. Lohr, M.P. Pignone Literacy and health outcomes. A systematic review of the literature J Gen Intern Med, 19 (2004), pp. 12281239

[4] N.D. Berkman, S.L. Sheridan, K.E. Donahue, D.J. Halpern, K. Crotty Low health literacy and health outcomes: an updated systematic review Ann Intern Med, 155 (2011), pp. 97107

[5] I. Nielsen-Bohlman, A.M. Panzer, D.A. Kindig, Health Literacy: A prescription to end confusion The National Academic Press, Washington, DC (2004)

[6] K. Sørensen, S. Van den Broucke, J. Fullam, G. Doyle, J. Pelikan, Z. Slonska, et al. Health literacy and public health: a systematic review and integration of definitions and models BMC Public Health, 12 (2012), p. 80

[7] E.V. Estacio Health literacy and community empowerment: it is more than just reading, writing and counting J Health Psychol, 18 (2013), pp. 1056-1068

[8] I. Kirsch, A. Jungleblut, L. Jenkins, A. Kolstad Adult literacy in America: a first look at the results of the National Adult Literacy Survey National Center for Education Statistics, US Department of Education, Washington, DC (1993)

[9] R.M. Parker, D.W. Baker, M.V. Williams, J.R. Nurss The test of functional health literacy in adults: a new instrument for measuring patients' literacy skills J Gen Intern Med, 10 (1995), pp. 537-541 
Heijmans, M., Waverijn, G., Rademakers, J., Vaart, R. van der, Rijken, M. Functional, communicative and critical health literacy of chronic disease patients and their importance for self-management. Patient Education and Counseling: 2015, 98(1), 41-48

[10] Institute of Medicine Health Literacy: a prescription to end confusion

National Academy Press, Washington, DC (2004)

[11] D. Nutbeam The evolving concept of health literacy Soc Sci Med, 67 (2008), pp. 20722078

[12] D. Nutbeam Health literacy as a public health goal: a challenge for contemporary health education and communication strategies into the 21st century Health Promotion Int, 15 (2000), pp. 259-267

[13] I. Rootman, D. Gordon-El-Bihbety A vision for a health literate Canada CPHA, Ottawa, ON, Canada (2008)

[14] K. Eichler, S. Wieser, U. Brugger The costs of limited health literacy: a systematic review Int J Public Health, 54 (2009), pp. 313-324

[15] P. Easton, V.A. Entwistke, B. Williams Health in the "hidden population" of people with low literacy. A systematic review of the literature BMC Public Health, 10 (2010), p. 459

[16] I. van der Heide, J. Wang, M. Droomers, P. Spreeuwenberg, J. Rademakers, E. Uiters

The relationship between health, education, and health literacy: results from the Dutch Adult Literacy and Life Skills Survey J Health Commun, 18 (2013), pp. 172-184

[17] R. Sudore, A. Metha, A. Simonsick, T.B. Harris, A.B. Newman, S. Satterfield Limited literacy in older people and disparities in health and healthcare access J Am Geriatr Soc, 54 (2006), pp. 770-776

[18] S.K. Smith, D. Nutbeam, K.J. McCaffery Insights into the concept and measurement of health literacy from a study of shared decision-making in a low literacy population J Health Psychol, 18 (2013), pp. 1011-1022

[19] A.J. Apter, F. Wan, S. Reisine, B. Bender, C. Rand, D.K. Bogen, et al. The association of health literacy with adherence and outcomes in moderate-severe asthma J Allergy Asthma Immunol (2013), pp. 321-327

[20] M.M. Barry, M. D‘Eath, J. Sixsmith Interventions for improving population health literacy: insights from a rapid review of the evidence J Health Commun: Int Perspect, 18 (2013), pp. 1507-1522

[21] N.S. Morris, C.D. MacLean, B. Littenberg Literacy and health outcomes: a crosssectional study in 1002 adults with diabetes BMC Fam Pract, 14 (2006), p. 49

[22] H. Ishikawa, T. Takeuchi, E. Yano Measuring functional, communicative, and critical health literacy among diabetic patients Diabetes Care, 31 (2008), pp. 874-879

[23] M. Inoue, M. Takahashi, I. Kai Impact of communicative and critical health literacy on understanding of diabetes care and self-efficacy in diabetes management: a crosssectional study of primary care in Japan BMC Fam Pract, 14 (2013), p. 40

[24] A.Y. Lai, H. Ishikawa, T. Kiuchi, N. Mooppil, K. Griva Communicative and critical health literacy, and self-management behaviors in end-stage renal disease patients with diabetes on hemodialysis Patient Educ Couns, 91 (2013), pp. 221-227

[25] M.P. Fransen, T.M. van Schaik, T.B. Twickler, M.L. Essink-Bot Applicability of internationally available health literacy measures in the Netherlands J Health Commun, 16 (2011), pp. 134-149

[26] HLS-EU Consortium. Comparative report of health literacy in eight EU member states. The European Health Literacy Survey HLS-EU. Online publication: http://www.healthlitercay.eu.

[27] M. Rijken, M. van Kerkhof, J. Dekker, F.G. Schellevis Comorbidity of chronic diseases: effects of disease pairs on physical and mental functioning Qual Life Res, 14 (2005), pp. 45-55

[28] L. Hingstman, R.J. Kenens Figures from the registration of primary practices: survey 2009 [Cijfers uit de registratie van huisartsen: peiling 2009] NIVEL, Utrecht (2009)

[29] R. van der Vaart, C.H.C. Drosseart, E. Taal, P.M. ten Klooster, R.T.E. HilderinkKoertshuis, J.M. Klaase, et al. Validation of the Dutch functional, communicative and critical health literacy scales Patient Educ Couns, 89 (2012), pp. 82-88

[30] J. Petkov, P. Harvey, M. Battersby The internal consistency and construct validity of the partners in health scale: validation of a patient rated chronic condition self-management measure Qual Life Res, 19 (2010), pp. 1079-1085

[31] R.C. Maly, J.C. Frank, G.N. Marshall, M.R. DiMatteo, D.B. Reuben Perceived efficacy in patient-physician interactions (PEPPI): validation of an instrument in older persons

J Am Geriatr Soc, 46 (1998), pp. 889-894 
Heijmans, M., Waverijn, G., Rademakers, J., Vaart, R. van der, Rijken, M. Functional, communicative and critical health literacy of chronic disease patients and their importance for self-management. Patient Education and Counseling: 2015, 98(1), $41-48$

[32] P.M. ten Klooster, J.C. Oostveen van, L.C. Zandbelt, E. Taal, C.H.C. Drosseart, E.J. Harmsen, et al.Further validation of the 5-item Perceived Efficacy in Patient-Physician Interactions (PEPPI-5) scale in patients with osteoarthritis Patient Educ Couns, 87 (2012), pp. $125-130$

[33] H. Lamberts, M. Wood ICPC. International classification of primary care Oxford University Press, Oxford (1987)

[34] M. de Klerk, C. van Campen, J. ledema SCP-measure of functional disabilities based on AVO 2003 [SCP-maat voor lichamelijke beperkingen op basis van AVO 2003] SCP, Den Haag (2006)

[35] C.B. Terwee, S.D. Bot, M.R. de Boer, D.A. van der Windt, D.L. Knol, J. Dekker, et al. Quality criteria were proposed for measurement properties of health status questionnaires J Clin Epidemiol, 60 (2007), pp. 34-42

[36] L.T. Hu, P.M. Bentler Cutoff criteria for fit inndices in covariance structure analysis: conventional criteria versus new alternatives Struct Equ Model, 6 (1999), pp. 1-55

[37] S. Sykes, J. Wills, G. Rowlands, K. Popple Understanding critical health literacy: a concept analysis BMC Public Health, 13 (2013), p. 150

[38] R.H. Osborne, R.W. Batterham, G.R. Elsworth, M. Hawkins, R. Buchbinder The grounded psychometric development and initial validation of the Health Literacy Questionnaire (HLQ) BMC Public Health, 13 (2013), p. 658

[39] D. Nutbeam Defining and measuring health literacy: what can we learn from literacy studies? Int J Public Health, 54 (2009), pp. 303-305

\section{TABLES AND FIGURES}

Table 1. Sample characteristics $(n=1.341)$.

\begin{tabular}{|l|l|l|l|l||}
\hline & \multicolumn{1}{|c|}{$\boldsymbol{n}$} & Percentage & Mean \pm SD & Range \\
\hline \hline Age (in years) & 1.341 & & $61.8 \pm 1.6$ & $17-93$ \\
\hline \hline$<45$ & 192 & 14 & & \\
\hline \hline $45-64$ & 486 & 36 & & \\
\hline \hline $65-74$ & 427 & 32 & & \\
\hline \hline 75 & 236 & 18 & & \\
\hline \hline Female & 740 & 55 & & \\
\hline Educational level & & & \\
\hline \hline Low & 414 & 32 & & \\
\hline \hline Intermediate & 566 & 43 & & \\
\hline \hline High & 320 & 25 & & \\
\hline \hline Living alone & 300 & 23 & \\
\hline \hline Income & & & \\
\hline \hline$€ 900-1600$ & 325 & 27 & \\
\hline \hline$€ 1600-€ 2100$ & 253 & 21 & \\
\hline \hline$€ 2100-2900$ & 301 & 25 & \\
\hline \hline$\geq € 2900$ & 317 & 27 & \\
\hline \hline Index disease & & & \\
\hline \hline
\end{tabular}


Heijmans, M., Waverijn, G., Rademakers, J., Vaart, R. van der, Rijken, M. Functional, communicative and critical health literacy of chronic disease patients and their importance for self-management. Patient Education and Counseling: 2015, 98(1), 41-48

\begin{tabular}{|c|c|c|c|c|}
\hline & $\bar{n}$ & Percentage & Mean \pm SD & Range \\
\hline Cardiovascular disease & 225 & 17 & & \\
\hline Lung diseases & 287 & 22 & & \\
\hline Musculoskeletal disease & 175 & 13 & & \\
\hline Cancer & 86 & 6 & & \\
\hline Diabetes mellitus & 200 & 15 & & \\
\hline Neurological disease & 96 & 7 & & \\
\hline Digestive disease & 54 & 4 & & \\
\hline Other chronic disease & 214 & 16 & & \\
\hline \multicolumn{5}{|l|}{ Number of chronic diseases } \\
\hline One & 684 & 51 & & \\
\hline Two & 378 & 29 & & \\
\hline Three & 164 & 12 & & \\
\hline Four and more & 111 & 8 & & \\
\hline \multicolumn{5}{|l|}{ Functional disability } \\
\hline No or mild & 869 & 69 & & \\
\hline Moderate to severe & 400 & 31 & & \\
\hline Illness duration (years post-diagnosis) & 1.316 & & $12.0 \pm 9.0$ & $0-67$ \\
\hline$\leq 2$ & 55 & 5 & & \\
\hline $2-5$ & 174 & 14 & & \\
\hline $5-10$ & 439 & 33 & & \\
\hline$\geq 10$ & 648 & 49 & & \\
\hline \multicolumn{5}{|l|}{ Self-management (PIH-NL) } \\
\hline Coping & 1.216 & & $6.4 \pm 1.4$ & $0-8$ \\
\hline Active role & 1.267 & & $7.2 \pm 1.0$ & $0-8$ \\
\hline Knowledge & 1.305 & & $6.7 \pm 1.1$ & $0-8$ \\
\hline Symptom recognition and monitoring & 1.298 & & $6.8 \pm 1.5$ & $0-8$ \\
\hline PIH total score & 1.172 & & $6.8 \pm .8$ & $1.5-8$ \\
\hline $\begin{array}{l}\text { Confidence to act in medical } \\
\text { consultations }\end{array}$ & 1.255 & & $\mid 4.0 \pm .7$ & $\mid 1-5$ \\
\hline
\end{tabular}

Fig. 1. Standardized parameter estimates for the correlated 3-factor model of the HL-scales $(n=1.193)$. Rectangles represent the items from the questionnaire. The ellipses represent the latent constructs (factors). Values on the arrows between the factors and the items are standardized factor loadings. Values left of the items are the error variances. Values between the factors represent correlations between the factors. 
Heijmans, M., Waverijn, G., Rademakers, J., Vaart, R. van der, Rijken, M. Functional, communicative and critical health literacy of chronic disease patients and their importance for self-management. Patient Education and Counseling: 2015, 98(1), 41-48

In reading instructions or leaflets from hospitals/phamacies, how often do you find...
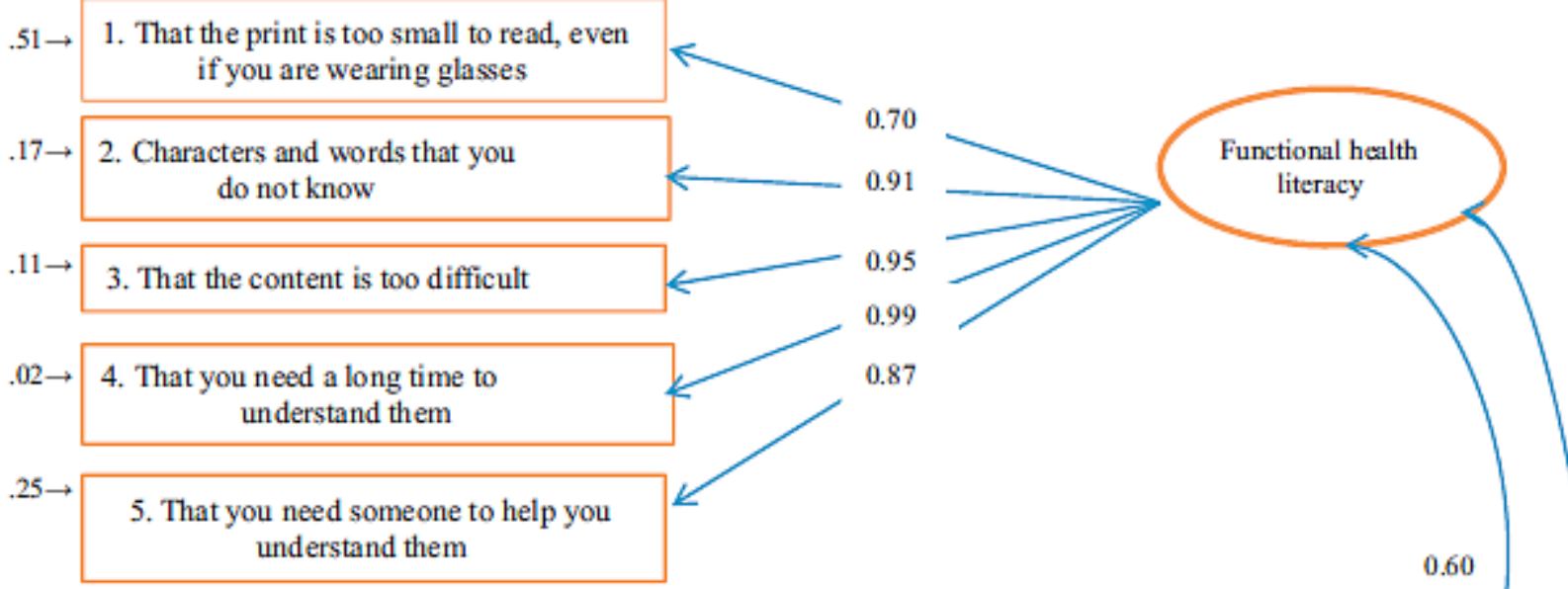

Since being diagnosed when you were ill, how difficult it is for you to..

$.33 \rightarrow \begin{gathered}\text { 6. Collect information from various } \\ \text { sources }\end{gathered}$
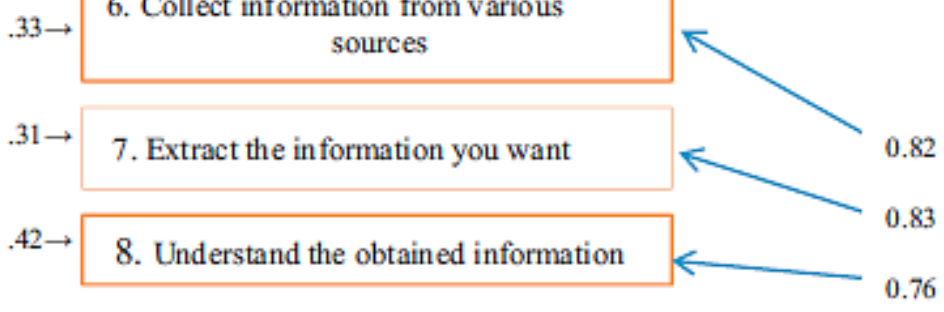

9. Communicate your thoughts about your illness to others
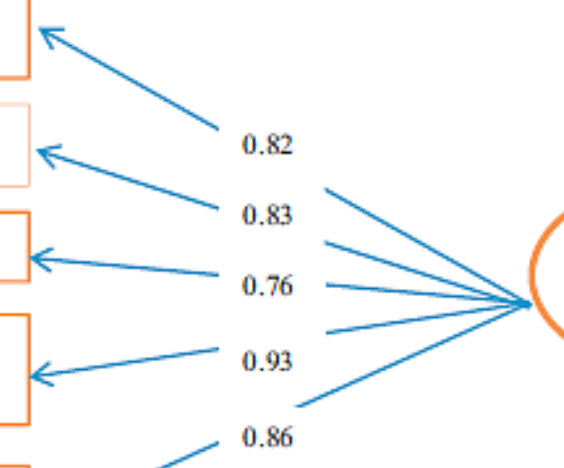

$.27 \rightarrow$

10. Apply the obtained information to your daily life

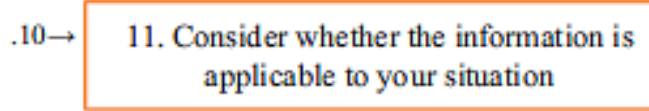

$.21 \rightarrow \quad 12$. Consider the validity and reliability of the information

$.19 \rightarrow$

13. Check whether the information is valid and reliable

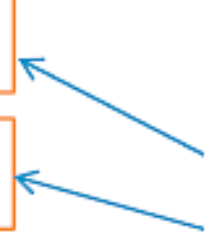

.16 $\rightarrow \quad$ 14. Collect information to make heal th-related decisions

${ }^{1}$ Rectangles represent the items from the questionaire. The ellipses represent the latent constructs (factors). Values on the arrows between the factors and the items are standardized factor loadings. Values left of the items are the error variances. Values between the factors represent correlations between the factors. 
Heijmans, M., Waverijn, G., Rademakers, J., Vaart, R. van der, Rijken, M. Functional, communicative and critical health literacy of chronic disease patients and their importance for self-management. Patient Education and Counseling: 2015, 98(1), 41-48

Table 2. Health literacy scores of chronic disease patients.

\begin{tabular}{|c|c|c|c|c|c|c|}
\hline \multirow{2}{*}{ Health literacy } & \multirow{2}{*}{$n$} & \multirow{2}{*}{$\|$ Mean \pm SD } & \multicolumn{4}{|c|}{ Frequency of scores (rounded) $^{\mathrm{a}}$} \\
\hline & & & $\overline{1}$ & 2 & $\overline{3}$ & 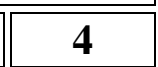 \\
\hline Functional & 1.256 & $3.2 \pm 0.7$ & $2 \%$ & $14 \%$ & $42 \%$ & $42 \%$ \\
\hline Communicative & 1.205 & $3.1 \pm 0.7$ & $2 \%$ & $15 \%$ & $51 \%$ & $32 \%$ \\
\hline Critical & 1.194 & $2.7 \pm 0.8$ & $7 \%$ & $41 \%$ & $36 \%$ & $16 \%$ \\
\hline Total score & 1.217 & $3.0 \pm 0.6$ & $1 \%$ & $20 \%$ & $58 \%$ & $13 \%$ \\
\hline
\end{tabular}

a. Higher scores indicate better health literacy.

Table 3. Bivariate relationships between sample characteristics and health literacy scales.

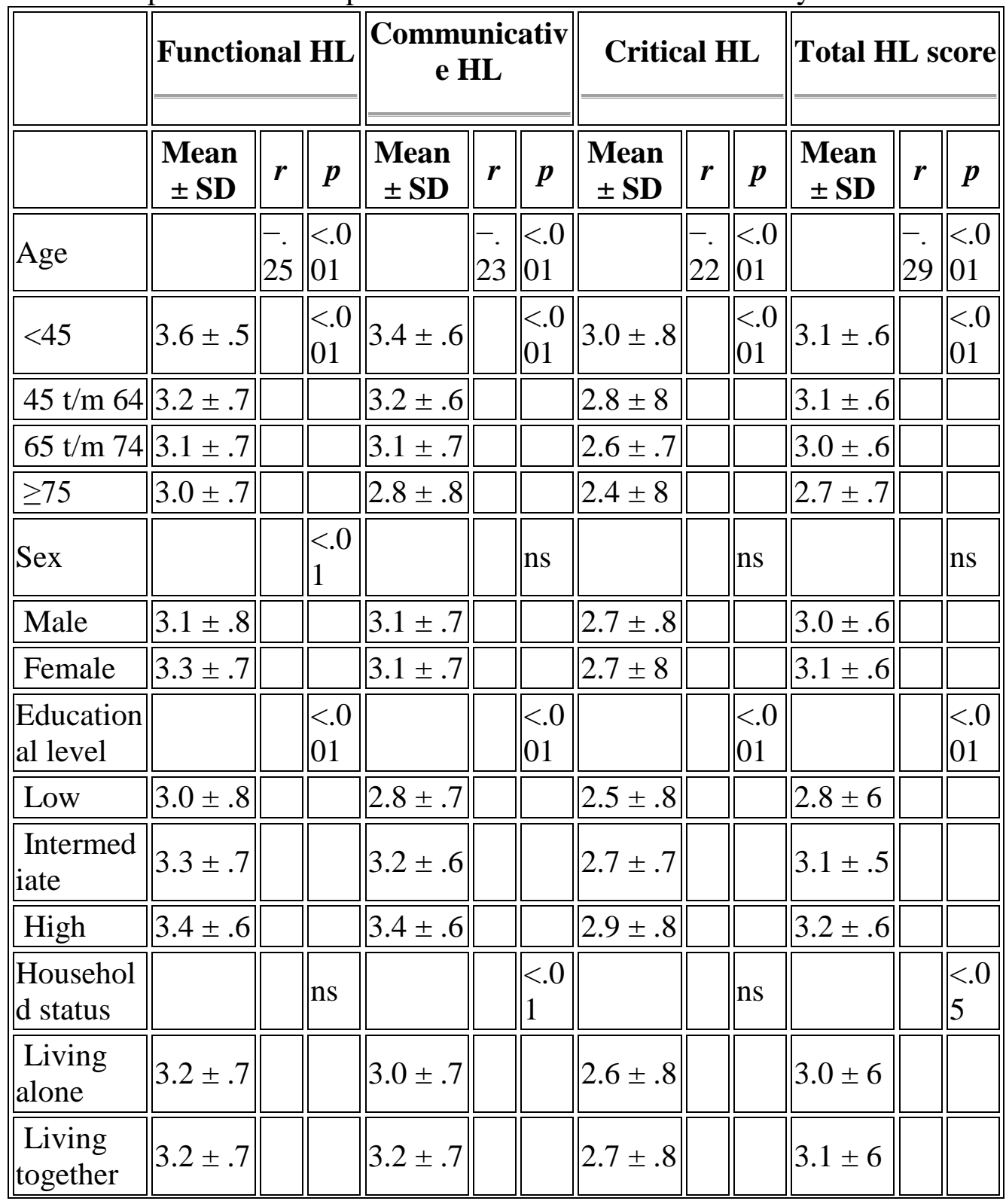


Heijmans, M., Waverijn, G., Rademakers, J., Vaart, R. van der, Rijken, M. Functional, communicative and critical health literacy of chronic disease patients and their importance for self-management. Patient Education and Counseling: 2015, 98(1), 41-48

nivel

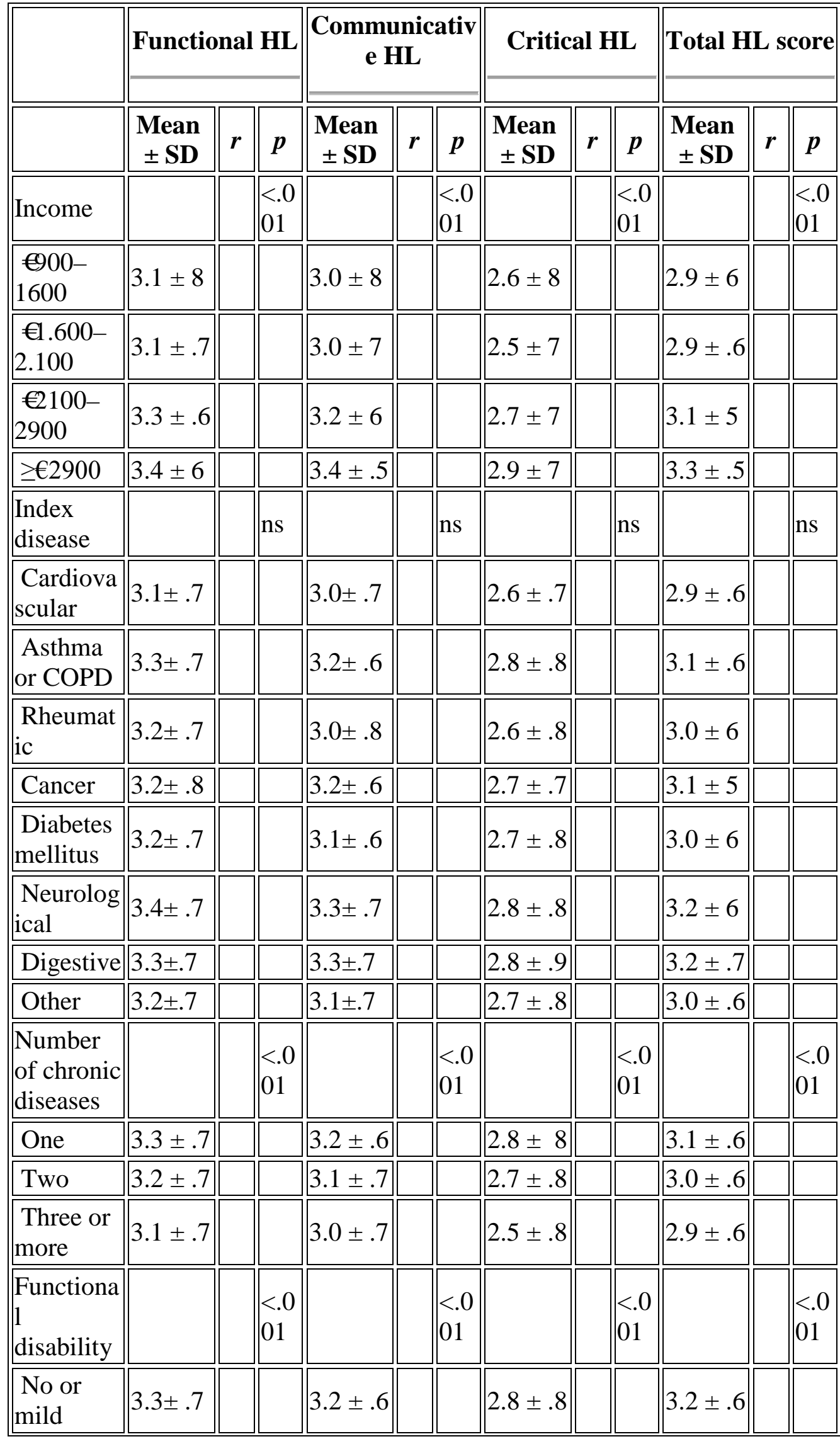


Heijmans, M., Waverijn, G., Rademakers, J., Vaart, R. van der, Rijken, M. Functional, communicative and critical health literacy of chronic disease patients and their importance for self-management. Patient Education and Counseling: 2015, 98(1), 41-48

nivel

\begin{tabular}{|c|c|c|c|c|c|c|c|c|c|c|c|c|}
\hline & \multicolumn{3}{|c|}{ Functional HL } & \multicolumn{3}{|c|}{$\begin{array}{c}\text { Communicativ } \\
\text { e HL }\end{array}$} & \multicolumn{3}{|c|}{ Critical HL } & \multicolumn{3}{|c|}{ Total HL score } \\
\hline & \begin{tabular}{|c} 
Mean \\
\pm SD \\
\end{tabular} & $r$ & $p$ & \begin{tabular}{|c|} 
Mean \\
\pm SD \\
\end{tabular} & $r$ & $\boldsymbol{p}$ & \begin{tabular}{|c} 
Mean \\
\pm SD \\
\end{tabular} & $r$ & $p$ & \begin{tabular}{|c|} 
Mean \\
\pm SD \\
\end{tabular} & $\boldsymbol{r}$ & $\boldsymbol{p}$ \\
\hline $\begin{array}{l}\text { Moderate } \\
\text { to severe }\end{array}$ & $3.0 \pm .7$ & & & $2.9 \pm .7$ & & & $\mid 2.5 \pm .8$ & & & $2.8 \pm 6$ & & \\
\hline $\begin{array}{l}\text { Illness } \\
\text { duration }\end{array}$ & & \begin{tabular}{|l||}
.- \\
06
\end{tabular} & \begin{tabular}{|l}
$<.0$ \\
5
\end{tabular} & & & \begin{tabular}{|l}
$<.0$ \\
1
\end{tabular} & & & & & 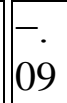 & \begin{tabular}{|l|}
$<.0$ \\
1
\end{tabular} \\
\hline
\end{tabular}

Table 4. Results of multiple regression analysis to predict aspects of self-management among chronic disease patients $(n=1.194)$.

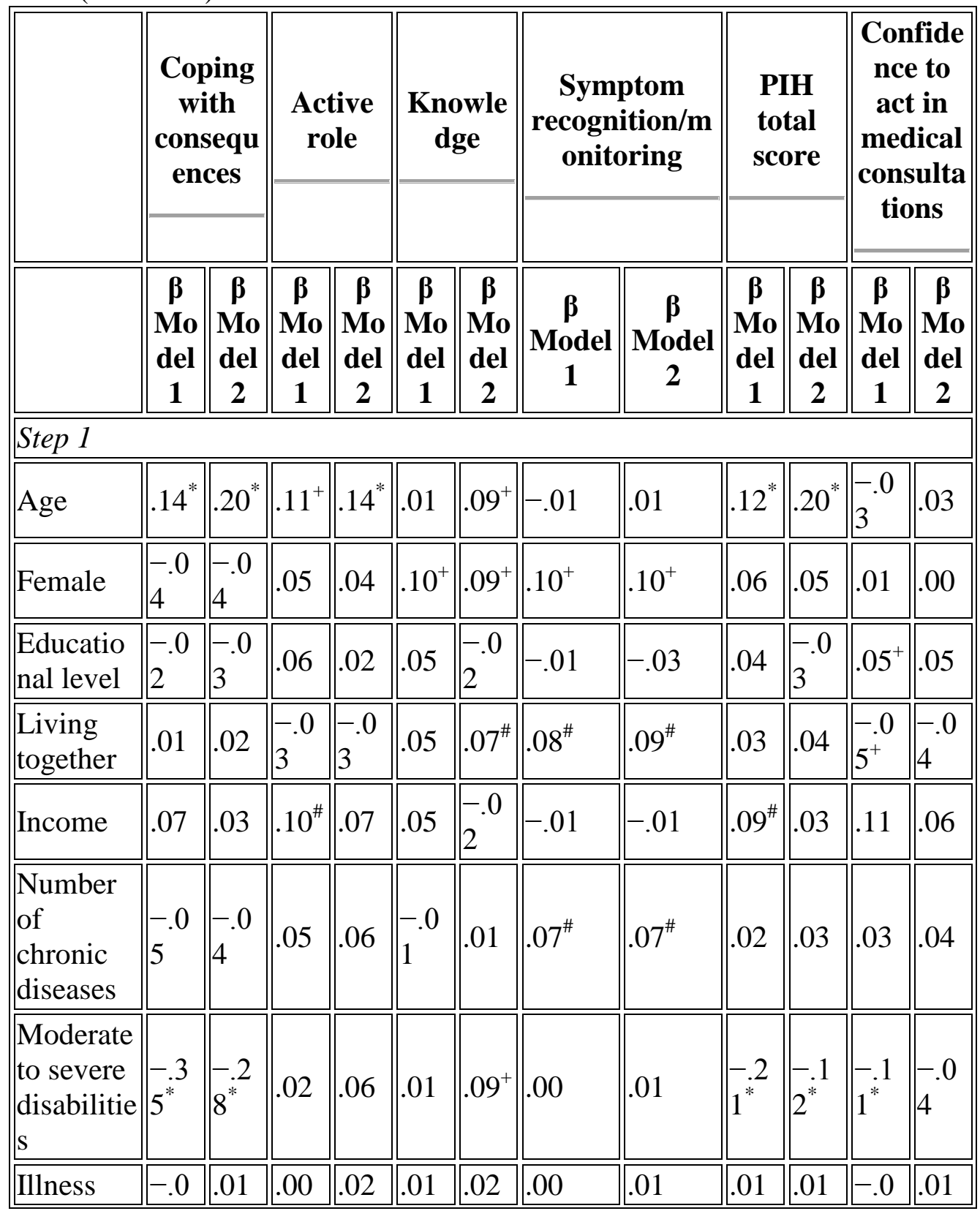


Heijmans, M., Waverijn, G., Rademakers, J., Vaart, R. van der, Rijken, M. Functional, communicative and critical health literacy of chronic disease patients and their importance for self-management. Patient Education and Counseling: 2015, 98(1), 41-48

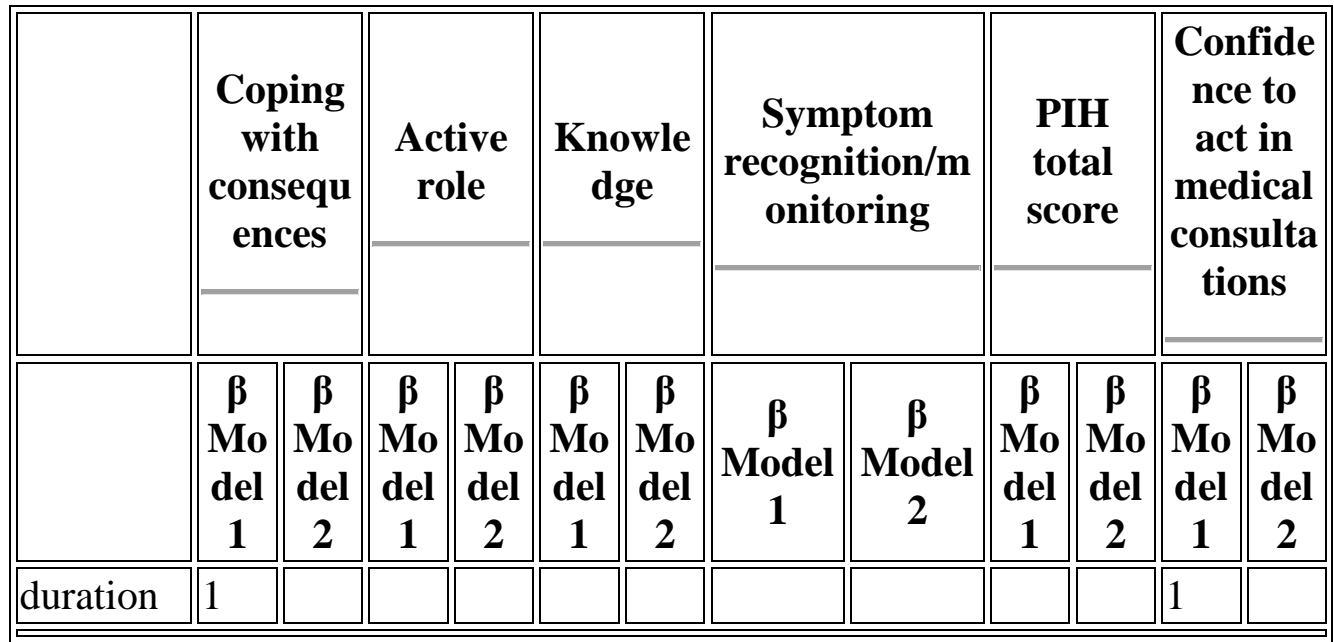

\begin{tabular}{|c|c|c|c|c|c|c|}
\hline \multicolumn{7}{|l|}{ Step 2} \\
\hline $\begin{array}{l}\text { Functiona } \\
\text { l HL }\end{array}$ & $.13^{*}$ & .02 & $.09^{+}$ & -.06 & $.09^{+}$ & $.11^{*}$ \\
\hline $\begin{array}{l}\text { Communi } \\
\text { cative HL }\end{array}$ & $.16^{*}$ & $.18^{*}$ & $.26^{*}$ & $.22^{*}$ & $.28^{*}$ & $.18^{*}$ \\
\hline \begin{tabular}{|l} 
Critical \\
HL
\end{tabular} & .07 & $.12^{*}$ & $.16^{*}$ & .02 & $.10^{+}$ & $\| .09^{\#}$ \\
\hline
\end{tabular}

\begin{tabular}{|l|l|l|l|l|l|l|l|l|l|l|l|l|l|l|}
\hline \hline Adjusted & $.15^{2}$ & $.22^{*}$ & .02 & $.06^{*}$ & $.02^{\#}$ & $.17^{*}$ & $.02^{\#}$ & $.06^{*}$ & $.07^{*}$ & $.20^{*}$ & $.05^{*}$ & $.13^{*}$ \\
\hline
\end{tabular}

$*<.001$.

$+<.01$.

$\#<.05$. 